\title{
A severity-of-illness score in patients with tuberculosis requiring intensive care
}

\author{
U Lalla, ${ }^{1} \mathrm{MB}$ ChB, MMed (Int), MRCP, FCP (SA), Cert Crit Care (SA); E M Irusen, ${ }^{1}$ MB ChB, FCP (SA), FCCP, PhD; \\ B W Allwood, ${ }^{1}$ MB BCh, DCH (SA), DA (SA), FCP (SA), Cert Pulm (SA), MPH, PhD; J J Taljaard, ${ }^{2}$ MB ChB, MMed (Int); \\ C F N Koegelenberg, ${ }^{1}$ MB ChB, MMed (Int), FCP (SA), FRCP, Cert Pulm (SA), PhD
}

\begin{abstract}
${ }^{1}$ Division of Pulmonology, Department of Medicine, Faculty of Health Sciences, Stellenbosch University and Tygerberg Academic Hospital, Cape Town, South Africa

${ }^{2}$ Division of Infectious Diseases, Department of Medicine, Faculty of Health Sciences, Stellenbosch University and Tygerberg Academic Hospital, Cape Town, South Africa
\end{abstract}

Corresponding author: U Lalla(usha@sun.ac.za)

\begin{abstract}
Background. We previously retrospectively validated a 6-point severity-of-illness score aimed at identifying patients at risk of dying of tuberculosis (TB) in the intensive care unit (ICU). Parameters included septic shock, HIV infection with a CD4 count $<200$ cells/ $\mu \mathrm{L}$, renal dysfunction, a ratio of partial pressure of arterial oxygen to fraction of inspired oxygen $(\mathrm{P} / \mathrm{F})<200 \mathrm{mmHg}$, a chest radiograph demonstrating diffuse parenchymal infiltrates, and no TB treatment on admission.

Objectives. To prospectively validate the severity-of-illness scoring system in patients with TB requiring intensive care, and to refine and simplify the score in order to expand its clinical utility.

Methods. We performed a prospective observational study with a planned post hoc retrospective analysis, enrolling all adult patients with confirmed TB admitted to the medical ICU of a tertiary hospital in Cape Town, South Africa, from 1 February 2015 to 31 July 2018 . The admission data of all adult patients with TB requiring admission to the ICU were used to calculate the 6-point severity-of-illness score and a refined 4-point score (based on the planned post hoc analysis). Descriptive statistics and $\chi^{2}$ or Fisher's exact tests (where indicated) were performed on dichotomous categorical variables, and $t$-tests on continuous data. Patients were categorised as hospital survivors or nonsurvivors.

Results. Forty-one of 78 patients (52.6\%) died. The 6-point scores of non-survivors were higher than those of survivors (mean (standard deviation (SD) 3.5 (1.3) v. 2.7 (1.2); $p=0.01$ ). A score $\geq 3$ v. $<3$ was associated with increased mortality $(64.0 \%$ v. $32.1 \%$; odds ratio (OR) 3.75 ; 95\% confidence interval (CI) $1.25-10.01 ; p=0.01$ ). Post hoc, a P/F ratio $<200 \mathrm{mmHg}$ and no TB treatment on admission failed to predict mortality, whereas any immunosuppression did. A revised 4-point score (septic shock, any immunosuppression, acute kidney injury and lack of lobar consolidation) demonstrated higher scores in non-survivors than survivors (mean (SD) 2.8 (1.1) v. 1.6 (1.1); $p<0.001$ ). A score $\geq 3$ v. $\leq 2$ was associated with increased mortality (78.4\% v. 29.3\%; OR 8.76; 95\% CI $3.12-24.59 ; p<0.001)$.

Conclusions. The 6-point severity-of-illness score identified patients at increased risk of death. We were able to derive and retrospectively validate a simplified 4-point score with superior predictive power.
\end{abstract}

S Afr Med J 2021;111(3):245-249. https://doi.org/10.7196/SAMJ.2021.v111i3.14609

Despite the presence of effective treatment, tuberculosis (TB) remains a significant challenge globally. In 2017, 1.3 million deaths among HIV-negative people and a further 300000 deaths among HIV-positive people were attributed to the disease worldwide. ${ }^{[1]}$ The mortality rate in patients with active pulmonary $\mathrm{TB}$ requiring mechanical ventilation ranges from $26 \%$ to $83 \%{ }^{[2]}$ Prognostic evaluation using severity-of-illness scores may be useful in developing strategies to improve outcome in the intensive care unit (ICU). However, the ideal prognostic score remains elusive. The Acute Physiology and Chronic Health Evaluation II (APACHE II) score, frequently used to estimate the probability of hospital mortality for patients admitted to the ICU, is completed 24 hours following ICU admission and has not been validated in the emergency department. ${ }^{[3]}$

We previously retrospectively validated a 6-point severity-ofillness score aimed at identifying ICU patients at risk of dying of TB. ${ }^{[4]}$ The parameters included septic shock, HIV infection with a CD4 count $<200$ cells $/ \mu \mathrm{L}$, renal dysfunction (creatinine $>140 \mu \mathrm{mol} / \mathrm{L}$ (male) or $>120 \mu \mathrm{mol} / \mathrm{L}$ (female)), arterial oxygen partial pressure to fractional inspired oxygen (P/F) ratio $<200 \mathrm{mmHg}$, a chest radiograph demonstrating diffuse parenchymal infiltrates, and no
TB treatment on admission. ${ }^{[4]}$ The scores were significantly lower in survivors compared with non-survivors (mean (standard deviation (SD)) 2.27 (1.47) v. 3.58 (1.08); $p<0.001$ ). Moreover, a score of $\geq 3$ was associated with significantly higher mortality than a score of $<3$ (64.6\% v. $20.0 \%$; odds ratio (OR) 7.29 ; $95 \%$ confidence interval (CI) $2.64-20.18 ; p<0.001)$.

\section{Objectives}

To prospectively validate the severity-of-illness scoring system in patients with $\mathrm{TB}$ requiring intensive care, and secondarily to potentially refine and simplify the score in order to expand its clinical utility.

\section{Methods}

\section{Study population and setting}

All adult patients (aged $\geq 18$ years) admitted to the medical ICU at Tygerberg Hospital, Cape Town, South Africa (SA), with the diagnosis of confirmed active TB were enrolled. Tygerberg Hospital, a 1380 -bed facility, is one of two referral centres in Cape Town rendering a tertiary service to a population of $\sim 1.5$ million 
people. In 2018, the incidence rate of TB in SA was $\sim 520 / 100000$ population. ${ }^{[1]}$

\section{Study design}

This prospective observational cohort study was conducted from 1 February 2015 to 31 July 2018 and was approved by the Stellenbosch University Health Research Ethics Committee (ref. no. N14/10/). Patients were considered to have active TB if at least two of the following criteria were met: (i) smear positive for acid-fast bacilli or Xpert MTB/RIF (Cepheid, SA) on sputum, tracheal aspirate, or any other clinical specimen; (ii) culture positive for Mycobacterium tuberculosis on sputum, tracheal aspirate or any other clinical specimen; (iii) histopathological identification of TB granuloma on biopsied tissues; (iv) strong clinical suspicion of active TB; $(v)$ strong radiological evidence of active TB; and $(v i)$ pleural fluid with a lymphocyte predominance ( $>75 \%$ lymphocytes and/or lymphocyte/ neutrophil ratio $>0.75$ ) with adenosine deaminase $>40 \mathrm{IU} / \mathrm{L}$. A strong clinical suspicion of active TB required at least two of four constitutional symptoms (loss of weight with accompanying fever, night sweats, productive cough, and loss of appetite for $>2$ weeks) as well as known TB contact or a history of previous pulmonary TB. Positive cultures were identified as $M$. tuberculosis and tested for susceptibility to rifampicin and isoniazid using the MTBDRplus line probe assay (Hain LifeSciences, Germany). The study included patients with both drug-susceptible TB and drug-resistant TB (DR-TB).
\end{abstract}

\section{Clinical data, laboratory tests, imaging and related investigations}

Patient demographics, comorbid disease, the presence of septic shock, the degree of hypoxaemia utilising the $\mathrm{P} / \mathrm{F}$ ratio and the presence of TB treatment were documented. Laboratory investigations included the white blood cell count, platelet count, serum haemoglobin, serum albumin, C-reactive protein, serum creatinine and alanine aminotransferase. Absolute CD4 counts were measured in HIVpositive patients. The admission chest radiograph of each patient was reviewed by two pulmonologists independently, who were blinded to the clinical data. The chest radiographs were classified as follows: (i) multilobar/diffuse involvement; (ii) lobar consolidation; (iii) cavitation; (iv) pleural effusion; $(v)$ isolated lymphadenopathy; or $(v i)$ normal. The APACHE II score was calculated after the first 24 hours in the ICU. The 6-point severity-of-illness score for each study participant was determined from data obtained on ICU admission.

\section{Management and complications}

All patients were managed according to local guidelines and received maximal supportive therapy. The standard combination anti-TB treatment regimen was used unless significant renal or hepatic impairment or confirmed drug resistance was present. ${ }^{[5]}$ Standard diagnostic criteria for septic shock, renal failure and acute respiratory distress syndrome (ARDS) were employed. ${ }^{[6-8]}$

\section{Statistical analysis}

Data were analysed using SPSS 17.0 (IBM, USA). Descriptive statistics and $\chi^{2}$ or Fisher's exact tests (where indicated) were performed on dichotomous categorical variables, and $t$-tests on continuous data. Patients were categorised as hospital survivors or non-survivors. Based on our previous study, we estimated that a sample size of $\sim 80$ patients was needed to validate the original 6-point severity-of-illness score. ${ }^{[4]}$

\section{Post hoc analyses}

A planned post hoc analysis was performed to assess the significance of various parameters used in the severity-of-illness score as well as other markers of mortality and potentially derive a simplified (and potentially more practical) score with equal or higher predictive power. The more recently described Kidney Disease: Improving Global Outcomes (KDIGO) Clinical Practice Guideline for Acute Kidney Injury ${ }^{[9]}$ was used to define renal dysfunction in the revised severity-of-illness score.

\section{Results}

\section{Study population characteristics}

During the study period, a total of $78 \mathrm{~TB}$ patients (mean (standard deviation (SD)) age 36.1 (14.4) years, $n=40$ males) were admitted to the medical ICU, all of whom were included in the study. The majority of the patients $(n=76 ; 97 \%)$ had active pulmonary TB. Eleven of these patients had disseminated disease. Two patients had evidence of extrapulmonary TB exclusively. Extrapulmonary involvement in all patients, including those with concomitant pulmonary involvement, included pleural $(n=16)$, pericardial $(n=4)$ and neurological $(n=5)$ disease, TB lymphadenitis $(n=2)$ and abdominal TB $(n=5)$. Seventeen patients $(21.8 \%)$ were on TB treatment at the time of admission. Twenty-four patients (30.8\%) were HIV-infected, of whom 17 had a CD4 count $<200$ cells/ $\mu \mathrm{L}$. Other forms of immunocompromised states included diabetes mellitus $(n=10)$ and treatment with immunosuppressive drugs $(n=3)$.

The mean (range) duration of ICU admission was $7.4(1-22)$ days. The most common indication for admission directly related to TB was acute respiratory failure $(n=51 ; 65.4 \%)$. ARDS was present in 5 survivors and 6 non-survivors in this group of patients. Other indications included a decreased level of consciousness $(n=7)$, upper airway obstruction $(n=1)$ and cardiac tamponade $(n=1)$. Eighteen patients were admitted for concomitant disease unrelated to TB.

Tracheal aspirates were obtained from all patients with presumed pulmonary TB, and the diagnosis was supported by a positive Xpert MTB/ RIF in all but 6 patients. Three patients were rifampicin resistant (DR$\mathrm{TB})$. The diagnosis of TB in the absence of direct microbiological proof or a positive Xpert MTB/RIF was based on a high clinical probability, combined with radiological evidence alone $(n=2)$, radiological and pleural fluid analysis $(n=2)$, radiological and cerebrospinal fluid (CSF) fluid analysis $(n=1)$ and CSF analysis alone $(n=1)$.

Twenty-one patients died in the ICU (ICU mortality 26.9\%) and a further 20 patients died in hospital following ICU discharge (in-hospital mortality $52.5 \%$ ).

\section{Predictors of mortality and the performance of the 6-point score}

The clinical, radiological and laboratory data of survivors and non-survivors are summarised in Tables 1 - 3. Of note is the fact that other forms of immunosuppression were strongly associated with increased mortality, as was renal impairment. Septic shock was a strong predictor of mortality (OR 5.21; 95\% CI 1.97 - 9.33). Patients with lobar consolidation had an increased likelihood of survival. Thrombocytopenia and hypolbuminaemia were associated with increased mortality, as was high serum creatinine. The 6-point severity of illness score predicted mortality (Table 4). A score of $\geq 3$ was associated with a higher mortality rate than a score of $<3$ ( $p=0.007$ and OR $3.75 ; 95 \%$ CI $1.41-10.01$ ).

\section{Post hoc analyses}

In view of the lack of a significant association with mortality of both $\mathrm{P} / \mathrm{F}<200 \mathrm{mmHg}$ and absence of TB treatment on admission, in conjunction with the strong association with other (non-HIV) immunocompromised states and the more recently described KDIGO guidelines for acute kidney injury, we proposed a refined score, 
Table 1. Population characteristics, survivors v. non-survivors

\begin{tabular}{|c|c|c|c|c|c|}
\hline Parameter & $\begin{array}{l}\text { All } \\
(N=78)\end{array}$ & $\begin{array}{l}\text { Survivors } \\
(N=37)\end{array}$ & $\begin{array}{l}\text { Non-survivors } \\
(N=41)\end{array}$ & OR $(95 \% \mathrm{CI})$ & $p$-value \\
\hline Sex (female), $n$ & 38 & 19 & 19 & $0.82(0.34-1.99)$ & 0.64 \\
\hline Age (years), mean (SD) & $36.1(14.4)$ & $33.0(11.8)$ & $38.8(16.1)$ & NA & 0.07 \\
\hline APACHE II, mean (SD) & $23.8(8.0)$ & $21.2(7.4)$ & $26.3(7.8)$ & NA & 0.01 \\
\hline Extrapulmonary TB, $n$ & 13 & 4 & 9 & $2.32(0.65-8.30)$ & 0.19 \\
\hline HIV positive, $n$ & 24 & 11 & 13 & $1.10(0.42-2.88)$ & 1 \\
\hline HIV with CD $4<200$ cells/ $\mu \mathrm{L}, n$ & 17 & 7 & 10 & $1.38(0.47-4.11)$ & 0.56 \\
\hline Other immunosuppression, $n$ & 13 & 1 & 12 & $14.8(1.83-121.38)$ & 0.002 \\
\hline TB treatment on ICU admission, $n$ & 17 & 11 & 6 & $0.41(0.13-1.24)$ & 0.18 \\
\hline
\end{tabular}

Table 2. Clinical characteristics, survivors v. non-survivors

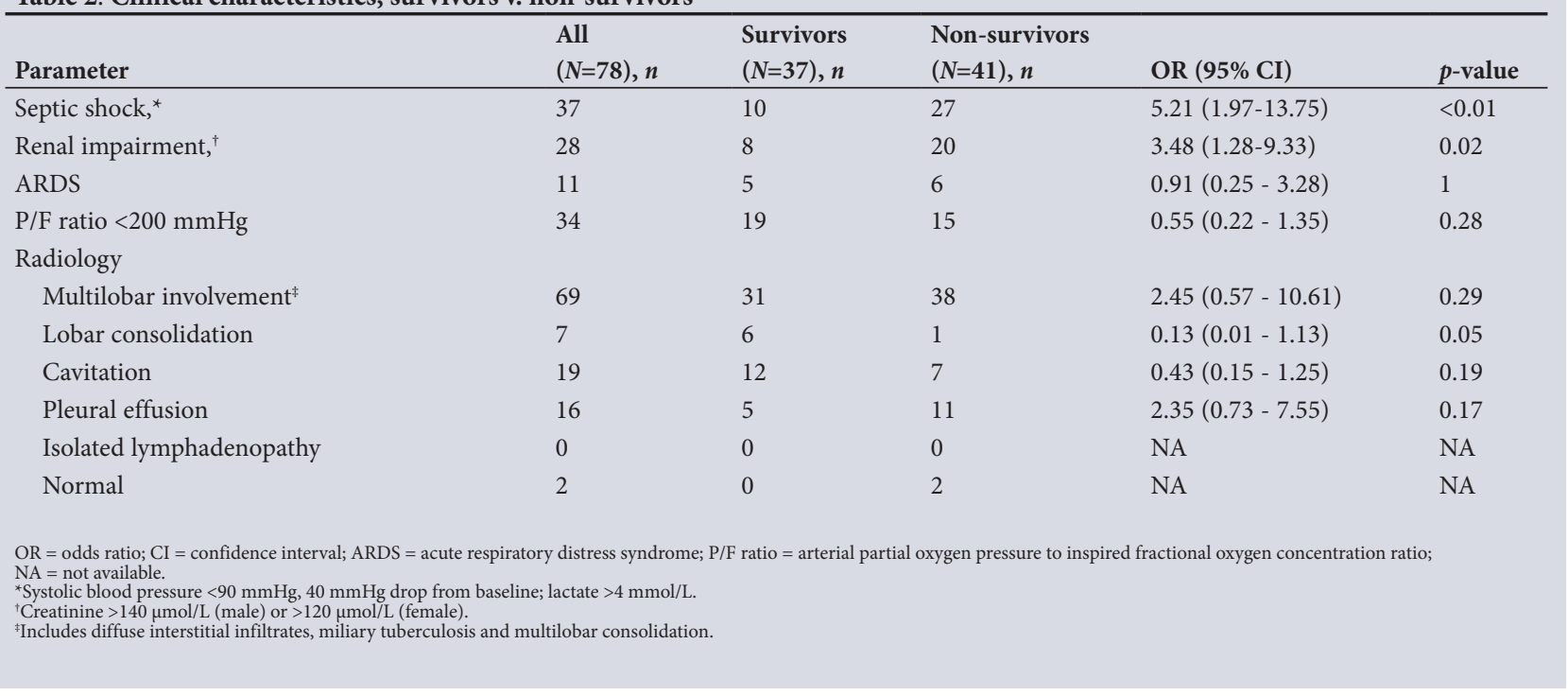

Table 3. Laboratory data, survivors v. non-survivors

\begin{tabular}{|c|c|c|c|c|c|}
\hline Parameter & Reference & $\begin{array}{l}\text { All } \\
(N=78) \text {, mean }(S D)\end{array}$ & $\begin{array}{l}\text { Survivors } \\
(n=37), \text { mean (SD) }\end{array}$ & $\begin{array}{l}\text { Non-survivors } \\
(n=41), \text { mean }(\mathrm{SD})\end{array}$ & $p$-value \\
\hline CD4 count $($ cells $/ \mu \mathrm{L})$ & $600-1500$ & $160(181)$ & $176(134)$ & $145(221)$ & 0.68 \\
\hline $\mathrm{P} / \mathrm{F}$ ratio $(\mathrm{mmHg})$ & $>300$ & $216(100)$ & 220 (109) & $229(91)$ & 0.79 \\
\hline White cell count $\left(\times 10^{9} / \mathrm{L}\right)$ & $4.0-11.0$ & $14.1(7.6)$ & $14.5(6.3)$ & $13.7(8.7)$ & 0.67 \\
\hline Platelet count $\left(\times 10^{9} / \mathrm{L}\right)$ & $150-400$ & $254(147)$ & $284(120)$ & $226(164)$ & 0.03 \\
\hline Haemoglobin $(\mathrm{g} / \mathrm{dL})$ & $12.0-15.0$ & $10.2(8.5)$ & $9.3(2.1)$ & $11.0(11.5)$ & 0.38 \\
\hline Serum albumin $(g / L)$ & $35-50$ & $23.7(6.8)$ & $26.6(7.0)$ & $21.3(5.7)$ & 0.001 \\
\hline C-reactive protein $(\mathrm{mg} / \mathrm{L})$ & $<5$ & $177(101)$ & $161(97)$ & $191(104)$ & 0.20 \\
\hline Creatinine $(\mu \mathrm{mol} / \mathrm{L})$ & $<90$ & $217(464)$ & $125(188)$ & $227(236)$ & 0.04 \\
\hline ALT (U/L) & $5-40$ & $112(323)$ & $99(374)$ & $122(281)$ & 0.76 \\
\hline
\end{tabular}

utilising 4 parameters: (i) septic shock; (ii) any immunocompromised state; (iii) acute kidney injury; and (iv) chest radiography not compatible with lobar consolidation. We subsequently retrospectively applied the 4-point score to the current cohort's admission data and found even higher discrimination (Table 5, Fig. 1). The 4-point scores of non-survivors were significantly higher than those of survivors (mean (SD) 2.8 (1.1) v. $1.6(1.1)$; $p<0.001)$. A score $\geq 3$ v. $\leq 2$ was associated with significantly increased mortality $(78.4 \%$ v. $29.3 \%$; OR 8.76; 95\% CI 3.12 - 24.59; $p<0.001$ ).

\section{Discussion}

In this prospective study, we found that the proposed 6-point severity-of-illness score accurately identified critically ill patients at increased risk of dying of TB. A score of $\geq 3$ was associated with a higher mortality rate, with an OR of $3.75(p=0.007)$. Moreover, we were able to refine and simplify the score. The refined score had even higher predictive power: a score of $\geq 3 \mathrm{v}$. $\leq 2$ was strongly associated with increased mortality $(78.4 \%$ v. $29.3 \%$; OR 8.76 ; $p<0.001)$. 
Table 4. Mortality rates according to the 6-point severity-of-illness score

\begin{tabular}{lllll}
\hline Score & All $(\boldsymbol{N = 7 8 ) , \boldsymbol { n }}$ & $\begin{array}{l}\text { Survivors } \\
(\boldsymbol{N}=\mathbf{3 7}), \boldsymbol{n}\end{array}$ & $\begin{array}{l}\text { Non-survivors } \\
(\boldsymbol{N}=\mathbf{4 1}), \boldsymbol{n}\end{array}$ & Mortality, \% \\
\hline$\leq 2$ & 28 & 19 & 9 & 32.1 \\
3 & 16 & 6 & 10 & 62.5 \\
$\geq 4$ & 32 & 12 & 22 & 68.8 \\
\hline$<3$ & 28 & 19 & 9 & 32.1 \\
$\geq 3$ & 50 & 18 & 32 & 64.0
\end{tabular}

Table 5. Mortality rates according to the revised 4-point severity-of-illness score

\begin{tabular}{lllll}
\hline Score & All $(\boldsymbol{N = 7 8 ) , \boldsymbol { n }}$ & $\begin{array}{l}\text { Survivors } \\
(\boldsymbol{N}=\mathbf{3 7}), \boldsymbol{n}\end{array}$ & $\begin{array}{l}\text { Non-survivors } \\
(\boldsymbol{N}=\mathbf{4 1}), \boldsymbol{n}\end{array}$ & Mortality, $\%$ \\
\hline$\leq 1$ & 23 & 18 & 5 & 21.7 \\
2 & 18 & 11 & 7 & 38.9 \\
3 & 25 & 6 & 19 & 76.0 \\
4 & 12 & 2 & 10 & 83.3 \\
\hline$\leq 2$ & 41 & 29 & 12 & 29.3 \\
$\geq 3$ & 37 & 8 & 29 & 78.4
\end{tabular}

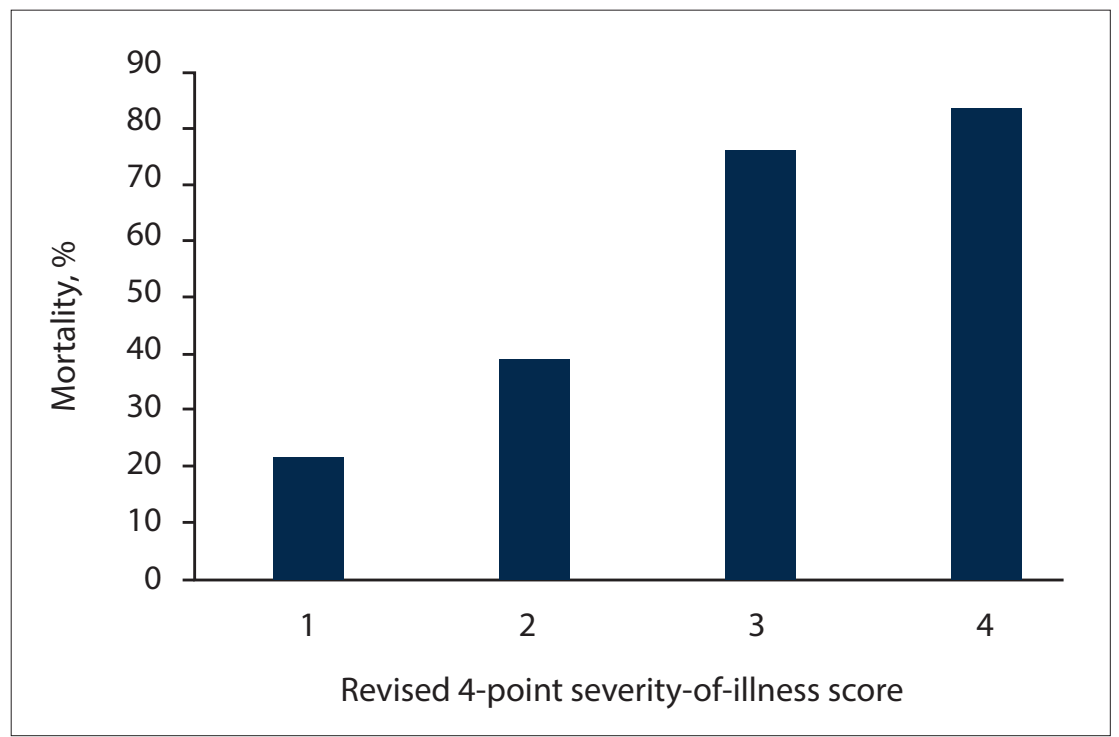

Fig. 1. Mortality rates according to the revised 4-point severity-of-illness score.

The need for mechanical ventilation in critically ill patients with $\mathrm{TB}$ is associated with increased mortality and prolonged ICU and hospital stays. ${ }^{[10]}$ Tatar et al. ${ }^{[11]}$ reported a mortality rate of $80.5 \%$ in 36 of 40 patients requiring mechanical ventilation in an ICU in Turkey, while in India, an ICU mortality rate of $44 \%$ was observed in 57 mechanically ventilated patients. ${ }^{[10]}$ We previously reported ICU mortality and hospital mortality of $44 \%$ and $59 \%$, respectively. ${ }^{[2]}$ The lower ICU (27\%) and in-hospital mortality rate (52.5\%) observed in the present study may in part be attributed to the recent introduction of the Xpert MTB/RIF as a rapid diagnostic test in the ICU, reducing the delay to diagnosis and treatment, which is a well-known risk factor for TB mortality. ${ }^{[12]}$

Factors significantly associated with mortality in the present study included a higher APACHE II score, hypolbuminaemia and thrombocytopenia, concurring with previous studies. ${ }^{[2,10,11,13]}$ Moreover, Tatar et al. ${ }^{[11]}$ and Ryu et al.$^{[14]}$ identified an APACHE II score of $>18$ and $>20$, respectively, as being predictive of death. The mean APACHE II score of 23.8 (21.2\% for survivors v. $26.3 \%$ for non-survivors) in our study highlights the high disease acuity in our cohort, a finding consistent with other studies with predominantly mechanically ventilated patients. ${ }^{[2,11]}$

The association between renal failure and TB-related mortality remains conflicting. ${ }^{[17,18]}$ We identified renal failure to be predictive of mortality in accordance with some, but not all, studies. ${ }^{[2,15,16]}$ In contrast to previous reports, we did not find a significant correlation with multilobar involvement on the chest radiograph and mortality. ${ }^{[17,18]}$ The vast majority of our patients had multilobar involvement on admission, which may explain this observation. However, the presence of lobar consolidation was found to be negatively associated with mortality. Additionally, we confirmed the lack of association between radiographic evidence of cavitation and mortality, as previously described. ${ }^{[4]}$ Septic shock was a strong predictor of mortality in our study. This is not surprising, considering the high mortality related to both mycobacterial and non-mycobacterial septic shock. Kethireddy et al. ${ }^{[19]}$ reported a $79 \%$ mortality rate in patients with mycobacterial septic shock compared with those with non-mycobacterial septic shock (49.7\%) in a multinational study. ${ }^{[19]}$ Duro et al. ${ }^{[20]}$ reported a significant association between severe sepsis/septic shock and mortality $(p=0.049$; OR 8.5 (95\% CI 0.931 - 77.598)) in 39 patients in Portugal.

Our study highlights the presence of any form of immunosuppression as a significant predictor of mortality. A contributing explanation for the poor outcomes observed in these patients may be the atypical radiographic presentation of $\mathrm{TB}$, potentially resulting in delayed diagnosis and commencement of anti-TB treatment. Approximately one-third of our patients were co-infected with HIV, a factor that did not contribute to mortality. This is in line with recent literature, possibly reflecting improving standards of care in this population. ${ }^{[20,21]}$ The lack of association between mortality and HIV infection in our study may additionally be explained by the fact that our non-HIV patients had a similar level of disease acuity and a high mortality rate. Although poorer outcomes have been reported in HIV-infected patients with a low CD4 count in critical illness, ${ }^{[22]} \mathrm{TB}$ itself may significantly reduce the $\mathrm{CD} 4$ count, with subsequent recovery after treatment. ${ }^{[23]}$

TB-related ARDS was not significantly associated with mortality in the present study, in keeping with our previous report. ${ }^{[2]}$ Additionally, we found no association between a $\mathrm{P} / \mathrm{F}$ ratio $<200 \mathrm{mmHg}$ and in-hospital mortality. This finding is in concordance with several studies that have shown that the $\mathrm{P} / \mathrm{F}$ ratio is not an independent predictor of mortality at the onset of ARDS. ${ }^{[24,25]}$ A plausible explanation may be that the $\mathrm{P} / \mathrm{F}$ ratio is a highly variable parameter, depending on the fraction of inspired oxygen and ventilator strategy utilised. Standardisation of ventilation strategies may improve its discriminatory power. ${ }^{[25]}$ Early initiation of empirical TB treatment, in view of the high burden of TB 
in our country, combined with earlier diagnosis utilising nucleic acid testing, may explain the lack of a significant association between the presence of TB treatment on admission and mortality in our cohort.

\section{Study strengths and limitations}

Our study has certain strengths. Unlike most current TB studies, which are retrospective, we prospectively enrolled a large number of patients in a single centre over a relatively short period of time, ensuring a consistent standard of care and limiting the impact of changes in critical care practice that occur over years. The simplicity and lack of a complex weighted scoring system of the revised 4-point score may lend itself to its use at all levels of care to develop strategies to improve outcome in the ICU. Future prospective research is needed to properly validate the revised 4-point score.

Our study may have some limitations. Resource constraints may have led to a selection bias towards patients with perceived better outcomes being preferentially admitted to the ICU. Delays in admission to the ICU, from the emergency department and other hospitals, may have resulted in delays in appropriate diagnosis and treatment and contributed to deteriorating clinical parameters.

\section{Conclusions}

The 6-point severity-of-illness score identified critically ill patients at increased risk of dying of TB. Moreover, we were able to derive and retrospectively validate a simplified 4-point score with superior predictive power, which may be particularly useful in a highincidence and resource-limited setting.

\section{Declaration. None.}

Acknowledgements. None.

Author contributions. UL and CFNK conceptualised the study. UL performed the data collection. UL and CFNK performed the data analysis and drafted the manuscript. All authors reviewed and ontributed to the final manuscript.

Funding. None.

Conflicts of interest. None.

1. World Health Organization. Global tuberculosis report 2019. Geneva: WHO, 2019. https://www.who. int/tb/publications/global_report/en/ (accessed 12 November 2019)

2. Balkema CA, Irusen EM, Taljaard JJ, Koegelenberg CFN. Tuberculosis in the intensive care unit: A prospective observational study. Int J Tuberc Lung Dis 2014;18(7):824-830. https://doi.org/10.5588/ ijtld.13.0044

3. Knaus WA, Draper EA, Wagner DP, Zimmerman JE. APACHE II: A severity of disease classification system. Crit Care Med 1985;13(10):818-829. https://doi.org/10.1097/00003246-198510000-00009
4. Koegelenberg CFN, Balkema CA, Jooste Y, Taljaard JJ, Irusen EM. Validation of a severity-ofillness score in patients with tuberculosis requiring intensive care unit admission. S Afr Med J illness score in patients with tuberculosis requiring in
2015;105(5):389-392. https://doi.org/10.7196/SAMJ.9148

5. Koegelenberg CFN, Nortje A, Lalla U, et al. The pharmacokinetics of enteral antituberculosis drugs in 5. Koegelenberg CFN, Nortje A, Lalla U, et al. The pharmacokinetics of enteral antituberculosis drugs in
patients requiring intensive care. S Afr Med J 2013;103(6):394-398. https://doi.org/10.7196/SAMJ.6344 patients requiring intensive care. S Afr Med J 2013;103(6):394-398. https://doi.org/10.7196/SAMJ.6344
Singer M, Deutschman CS, Seymour CW, et al. The Third International Consensus Definitions Singer M, Deutschman CS, Seymour CW, et al. The Third International Consensus Definition
for Sepsis and Septic Shock (Sepsis-3). JAMA 2016;315(8):801-810. https://doi.org/10.1001/ jama.2016.0287

7. Bellomo R, Ronco C, Kellum J, Mehta R, Palevsky P. Acute renal failure - definition, outcome measures, animal models, fluid therapy and information technology needs: The Second International Consensu Conference of the Acute Dialysis Quality Initiative (ADQI) Group. Crit Care 2004;8(4):R204-R212. https://doi.org/10.1186/cc2872

8. ARDS Definition Task Force; Ranieri VM, Rubenfeld GD, Thompson BT, et al. Acute respiratory distress syndrome: The Berlin Definition. JAMA 2012;307(23):2526-2533. https://doi.org/10.1001/ jama.2012.5669

9. Kidney Disease: Improving Global Outcomes (KDIGO) Acute Kidney Injury Work Group. KDIGO Clinical Practice Guideline for Acute Kidney Injury. Kidney Int Suppl 2012;2(1):1-138. https://doi. org/10.1038/kisup.2012.1

10. Muthu V, Dhooria S, Agarwal R, et al. Profile of patients with active tuberculosis admitted to a Muthu V, Dhooria S, Agarwal R, et al. Profile of patients with active tuberculosis admitted to a
respiratory intensive care unit in a tertiary care center of North India. Indian J Crit Care Med respiratory intensive care unit in a tertiary care center of No
2018;22(2):63-66. https://doi.org/10.4103/ijccm.IJCCM_491_17

11. Tatar D, Senol G, Kirkali C, Edipoglu O. Contributing factors to mortality rates of pulmonary tuberculosis in intensive care units. J Chinese Med Assoc 2018;81(7):605-610. https://doi.org/10.1016/j jcma.2018.02.003

12. Zahar JR, Azoulay E, Klement E, et al. Delayed treatment contributes to mortality in ICU patients with severe active pulmonary tuberculosis and acute respiratory failure. Intensive Care Med 2001;27(3):513520. https://doi.org/10.1007/s001340000849

13. Ferreira $\mathrm{MD}$, das Neves $\mathrm{CP}$, de Souza $\mathrm{AB}$, et al. Predictors of mortality among intensive care unit patients coinfected with tuberculosis and HIV. J Bras Pneumol 2018;44(2):118-124. https://doi. org $/ 10.1590 / s 1806-37562017000000316$

14. Ryu YJ, Koh WJ, Kang EH, et al. Prognostic factors in pulmonary tuberculosis requiring mechanical ventilation for acute respiratory failure. Respirology 2007;12(3):406-411. https://doi.org/10.1111/ ventilation for acute resp

15. Erbes R, Oettel K, Raffenberg M, Mauch H, Schmidt-Ioanas M, Lode H. Characteristics and outcome of patients with active pulmonary tuberculosis requiring intensive care. Eur Respir J 2006;27(6):12231228. https://doi.org/10.1183/09031936.06.00088105

16. Piqueras AR, Marruecos L, Artigas A, Rodriguez C. Miliary tuberculosis and adult respiratory distress syndrome. Intensive Care Med 1987;13(3):175-182. https://doi.org/10.1007/bf0025470

17. Madkour A, Fouda M, Mansour M. Outcome of active pulmonary tuberculosis patient requiring respiratory intensive care admission. Egypt J Bronchol 2014;28;8(2):79-86. https://doi. org/10.4103/1687-8426.145692

18. Valade S, Raskine L, Aout M, et al. Tuberculosis in the intensive care unit: A retrospective descriptive cohort study with determination of a predictive fatality score. Can J Infect Dis Med Microbiol 2012;23(4):173-178. https://doi.org/10.1155/2012/361292

19. Kethireddy S, Light RB, Mirzanejad Y, et al. Mycobacterium tuberculosis septic shock. Chest 2013;144(2):474-482. https://doi.org/10.1378/chest.12-1286

20. Duro RP, Dias PF, Ferreira AA, et al. Severe tuberculosis requiring intensive care: A descriptive analysis. Crit Care Res Pract 2017;2017:9535463. https://doi.org/10.1155/2017/9535463

21. Silva DR, Menegotto DM, Schulz LF, Gazzana MB, Dalcin PTR. Mortality among patients with tuberculosis requiring intensive care: A retrospective cohort study. BMC Infect Dis 2010;10:54. https:// doi.org/10.1186/1471-2334-10-54

22. Croda J, Croda MG, Neves A, de Sousa dos Santos S. Benefit of antiretroviral therapy on survival of human immunodeficiency virus-infected patients admitted to an intensive care unit. Crit Care Med 2009;37(5):1605-1611. https://doi.org/10.1097/CCM.0b013e31819da8c7

23. Skogmar S, Schön T, Balcha TT, et al. CD4 cell levels during treatment for tuberculosis (TB) in Ethiopian adults and clinical markers associated with CD4 lymphocytopenia. PLoS ONE 2013;8(12):e83270 https://doi.org/10.1371/journal.pone.0083270

24. Chen W, Janz DR, Shaver CM, Bernard GR, Bastarache JA, Ware LB. Clinical characteristics and outcomes are similar in ARDS diagnosed by oxygen saturation/ $/ \mathrm{Fio}_{2}$ ratio compared with $\mathrm{Pao} / \mathrm{Fio}$ ratio. Chest 2015;148(6):1477-1483. https://doi.org/10.1378/chest.15-0169

25. Villar J, Pérez-Méndez L, Blanco J, et al.; Spanish Initiative for Epidemiology, Stratification, and Therapies for ARDS (SIESTA) Network. A universal definition of ARDS: The $\mathrm{PaO}_{2} / \mathrm{FiO}_{2}$ ratio under a standard ventilatory setting - a prospective, multicenter validation study. Intensive Care Med 2013;39(4):583-592. https:///oi.org/10.1007/s00134-012-2803-x

Accepted 8 October 2020 